\title{
A RETÓRICA MUSICAL DA MPB: \\ UMA ANÁLISE DE DUAS CANÇÕES BRASILEIRAS ${ }^{1}$
}

\author{
Acácio Tadeu de Camargo Piedade ${ }^{2}$, Allan Medeiros Falqueiro ${ }^{3}$
}

PALAVRAS-CHAVE: Retórica musical; análise; canção.

RESUMO: Este artigo tem a retórica musical como objeto de estudo principal. Inicialmente, comentaremos o sistema retórico-musical do período barroco, e em seguida apresentaremos uma análise musical de duas canções da MPB procurando aplicar esta teoria. Estas canções apresentam aspectos opostos, e procuraremos interpretar esta dualidade conforme o sistema retórico-musical.

\section{INTRODUÇÃO}

A disciplina retórica nasceu na Grécia antiga, por volta do século $\mathrm{V}$ a.C., e teve como principais autores Aristóteles, Cícero e Quintiliano. Ainda no século XV fazia parte da educação básica, e "todo homem estudado era um ótimo retórico" (BUELOW, 1980, p.793). A retórica pode ser definida como o estudo da produção e análise do discurso sob a perspectiva da eloqüência e persuasão (CANO, 2000, p.7).

A música, como todas as outras artes, foi muito influenciada pela retórica durante os séculos XVI, XVII e XVIII, período no qual esta disciplina alcançou seu auge. Diversos tratados foram escritos entre 1535 e 1792 relacionando música e retórica, com o nome genérico de musica poetica (CANO, 2000, p.7). A partir do século XVIII, então, a retórica como um todo entrou em decadência, e somente no final do século XX pesquisadores começaram a se interessar novamente pelo assunto.

\section{O SISTEMA RETÓRICO MUSICAL}

O termo musica poetica foi utilizado pela primeira vez por Listenius, em seu tratado Musica, de 1537 (CANO, 2000, p.39). Os estudos musicais da época eram divididos em 3 áreas: musica pratica, musica teorica e musica poetica. Musica pratica se referia ao estudo dos manuais de execução, musica teorica tratava das questões teóricas sobre o som e da importância da música para os homens. Já a musica poetica (o termo poetica na língua grega se relaciona à idéia de "criar") tratava da composição musical, sendo a retórica da música uma das áreas estudadas. Os principais teóricos da época foram Listenius, Burmeister, Calvisius, Lippius, Kaldenbach, Nucius, Mattheson, Spiess, Heinichen, Bernhard, Mersenne, Kircher (CANO, 2000).

A música ocidental pode ser pensada como constituindo uma espécie de discurso, sendo assim que em uma peça musical pode haver uma concatenação de unidades que podem ser "atribuídas de qualidade, ou éthos, isto por meio de convenção cultural (diga-se, histórica e tácita)" (PIEDADE, 2006, p. 64). A relação entre retórica e música vai neste sentido, sendo que no período barroco, através das convenções expressas nos tratados mencionados, a música passou a ser estruturada, criada e embelezada como se fosse um bom discurso.

\footnotetext{
1 Estudos de música popular: contribuição para a musicologia brasileira CEART/UDESC. 2 Orientador, Professor do Departamento de Música - Centro de Artes.

3 Acadêmico do Curso de Licenciatura em Música - CEART/UDESC, bolsista de iniciação científica do PROBIC/CNPq.
} 
Um dos objetivos fundamentais da aplicação de princípios retóricos na música foi o de proporcionar ao discurso musical a possibilidade de despertar, mover e controlar os afetos do público, tal como os oradores faziam com o discurso falado (CANO, 2000, p.43).

Tais afetos são estados emocionais idealizados, tais como amor, tristeza, ódio, felicidade, dúvida, esperança, entre outros. Cristalizadas em certas figurações musicais, tais afetos habitavam as peças da época, tal como eram ouvidas, embora uma verdadeira teoria dos afetos não tenha sido constituída.

\begin{abstract}
Desde o século XIX, livros sobre a música barroca têm se referido constantemente a uma então chamada Doutrina dos Afetos, mas, em fato, nenhuma compreensiva e organizada teoria de como os afetos tinham que ser utilizados na música nunca foi estabelecida na teoria Barroca (BUELLOW, 1980, p.800).
\end{abstract}

Citado por Cano (2000, p.47) e Buelow (1980, p.801) como uma das principais influências filosóficas sobre os afetos no campo da música, a obra Les pasions de l'âme, de René Descartes, publicada em 1649, revelava que, para o autor, os afetos eram as paixões da alma causadas pelos movimentos dos espiritus animales através do sangue, gerando assim os sentimentos (CANO, 2000, p.47). Os afetos, enquanto realidade biológica, influenciavam tanto na composição como na execução musical.

Conforme os tratadistas da época, para se alcançar e mover os afetos dos ouvintes é necessário o uso das figuras retóricas, análogas às figuras de linguagem no caso da literatura, aliás, uma versão musical das mesmas, servindo para enfatizar o discurso musical. Outra forma de se mover os afetos dos ouvintes seria pela escolha da tonalidade e do modo da música. Não havia, entretanto, convergência absoluta nas opiniões. Por exemplo, ao se escrever uma música em Fá menor, ela transmitirá aos ouvintes um caráter deprimido, choroso, isto conforme Charpentier; ou ansiedade, tristeza, desespero e relaxamento, segundo Mattheson; já Rameau menciona ternura, lamento e depressão (CANO, 2000, p.66). Estes três teóricos realizaram uma análise dos afetos em cada uma das tonalidades e modos, havendo discrepâncias; mas, em sua maioria, as opiniões são convergentes. Entretanto, "nenhuma tonalidade pode ser tão triste ou alegre por si mesma que não possa representar também um sentimento oposto" (MATTHESON apud CANO, 2000, p.66). Portanto, tonalidade e modo são fatores que podem apenas significar um afeto potencial geral, não que já se possa saber como será uma música inteira somente pela tonalidade.

Para a retórica clássica de Aristóteles, Cícero e Quintiliano, o discurso está dividido em cinco fases preparatórias: inventio, dispositio, elocutio, memoria e pronunciatio. Segundo CANO (2000, p.73), a memoria foi a única parte que não foi transmitida para as outras artes que não a literatura, caindo em desuso: "a memoria é a única parte do sistema retórico que não foi sequer mencionada pelos tratadistas musicais do Barroco" (CANO, 2000, p.94). O inventio é onde se criam os argumentos que virão a fazer parte do discurso. No dispositio, tais argumentos são ordenados e distribuídos em momentos do discurso. Conforme Cano (2000, p.82), existem diversas formas de organização do dispositio, sendo que ele adota uma divisão em seis partes: exordium, narratio, propositio, confutatio, confirmatio e peroratio. Na Idade Média, era comum se dividir esta parte em initium, medium e finis (CANO, 2000, p.82). O exordium é a introdução do discurso, "é a passagem do silêncio ao som" (CANO, 2000, p.82). O narratio é a apresentação dos fatos. O propositio é a enunciação da tese fundamental que sustenta o discurso. O confutatio é a defesa desta tese, onde se apresentam os argumentos que a confirmem. O confirmatio é o retorno à tese fundamental. Por fim, o peroratio é o epílogo, alguma conclusão ou ênfase 
da tese. Pode existir uma espécie transição (transitus) entre os momentos, e, entretanto, tais momentos podem ser omitidos, trocados, modificados. Segundo Mattheson, nem todas as composições musicais seguiam rigidamente estas regras (MATTHESON apud BUELOW, 1980, p.794).

O elocutio é a parte onde se coloca em palavras o material inventado e organizado anteriormente, no caso da música, é o processo final da composição. Conta com certos artifícios para a melhora do discurso, como clareza e beleza. No caso da música, o artifício principal é o decoratio, que, segundo Cano (2000, p.93), é a parte mais conhecida do sistema retórico. É no decoratio que estão presentes as figuras retóricas que, para Buelow (1980, p.794), são técnicas usadas para embelezar o discurso de uma forma mais passional e para ilustrar ou enfatizar palavras. Através da escolha de determinadas figuras, o discurso musical dota-se de uma personalidade própria. Como afirma Cano (op.cit.), a figura torna o discurso belo, agradável, atrativo para quem o escuta: as figuras determinam o estilo (op.cit.p.102). As figuras são responsáveis por mover os afetos e assim cumprir o papel que a música possuía no período Barroco: movere, delectare e docere.

$\mathrm{O}$ pronuntiatio é a parte da execução do discurso. O pronuntiatio aparece nos tratados de música do Barroco na forma de conselhos práticos sobre criação e interpretação musical.

Os textos musicais da música barroca, portanto, estão repletos de referências às figuras bem conhecidas na época. Através da leitura dos tratados e outros textos teóricos, pode-se proceder uma análise retórica deste repertório, recompondo as figurações musicais ali presentes. A análise retórica é a análise destas fases do discurso, principalmente das três primeiras, inventio, dispositio e elocutio, e das figuras empregadas. Com o intuito de se descobrir os argumentos, como foram organizados e de que forma foram empregados no momento da composição, procura-se descobrir o caráter da peça, seu discurso. Atualmente há diversos especialistas e publicações sobre o assunto (BARTEL, 1997; CAVAZOTTI, 2005). No caso da música brasileira, a dimensão retórica tem sido estudada por Piedade (2006), que procura tópicas retóricas que podem ser tomadas como constituintes da musicalidade brasileira em geral. Esta comunicação se alinha neste esforço, procurando contribuir com uma análise preliminar de aspectos retóricos em duas canções de MPB.

\section{AS CANÇÕES}

A canção, composição em verso (ANDRADE, 1989, p.87), pequena composição vocal, com ou sem acompanhamento (JACOBS, 1978, p.95), é um objeto de estudo de grande interesse musicológico. Para alguns autores, na canção a música está sobreposta por uma letra, servindo essencialmente como base significativa para a declamação desta (TATIT, 1994). O uso de estratégias musicais para enfatizar o conteúdo proposto pela letra acaba por ser algo muitas vezes empregado. Já Calvisius, tratadista barroco, afirmou em 1592 que a música vocal é superior à música instrumental porque, com duas classes de figuras retóricas atuando simultaneamente, "oferece prazer em dobro" (CALVISIUS apud CANO, 2000, p.41) $)^{4}$ É interessante pensar a canção como produto de um encontro entre musicalidade e linguagem que, dialogando, produzem uma narratividade que é guiada pela letra, mas não se orienta unicamente por ela. Ou seja, na canção, a música tem letra tanto quanto a letra tem música (BASTOS, 1996; FRITH, 1988). O que pretendemos aqui é buscar um sentido retórico em partes destas peças, utilizando alguns conceitos diretamente dos tratadistas barrocos.

$\mathrm{Na} \mathrm{MPB}$, é comum a composição em parceira em que um é responsável pela

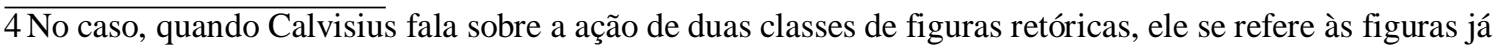
presentes no texto da composição e as presentes na música.

DAPesquisa, Florianópolis, v.2, n.4, p. 463-471, 2007. 
música e outro pela letra. Canções resultantes de duas grandes parcerias da história da MPB serão analisadas neste artigo: Tom Jobim e Vinícius de Moraes, com a música Eu sei que vou te amar, de 1959, e João Bosco e Aldir Blanc, com a música Incompatibilidade de gênios, de 1976. Nesta análise, estudaremos a relação letra/música empregando conceitos do sistema retórico-musical desenvolvido pelos tratadistas dos séculos XVII e XVIII.

A letra da canção Eu sei que vou te amar trata de um amor eterno, uma declaração de amor para toda a vida, mesmo sendo este um amor triste, cheio de sofrimento e fadado a ter que ser vivido à distância ${ }^{5}$. Já a letra da canção Incompatibilidade de gênios expressa $\mathrm{o}$ oposto: trata de um amor que, já consolidado através do casamento, acabou desgastado pela convivência e pela descoberta de uma incompatibilidade do casal.

Apesar da dualidade, as duas canções apresentam claramente uma mesma figura retórica musical: aquela que os teóricos do barroco chamariam de gradatio, que é a repetição em seqüência de um mesmo fragmento melódico em movimento ascendente ou descendente por grau conjunto (CANO, 2000, p.136) ${ }^{6}$. Estas figuras retóricas eram consideradas extremamente efetivas pelos tratadistas, contendo ainda um aspecto místico, pois o movimento ascendente se referia ao amor divino ou ao reino celeste (KIRCHER apud CIVRA 1991, p.128). Para além das significações que esta figura tinha no período do barroco, como pensar este gradatio nestas duas canções? É claro que ele está presente durante todo o decorrer das duas obras, mas em Eu sei que vou te amar é um movimento ascendente, enquanto na Incompatibilidade de gênios é descendente, acompanhando a oposição expressa nas letras das duas músicas. Curiosamente, para os tratadistas do barroco, a figura musical de movimento descendente, chamada catabasis, expressava sentimento de inferioridade e situações deprimentes, e mesmo um descendit ad inferos (CANO, 2000, p.152). Assim, as canções nos propõem uma associação entre a ascensão melódica gradual e a expressão de um grande amor, de um saber da imensidão deste amor, enquanto o caráter descendente se põe ao lado de um desamor tal que se tornou quase uma doença ${ }^{7}$.

Na música Eu sei que vou te amar, o argumento principal é o intervalo de terça, introduzido no exordium, ou seja, na introdução do discurso, pelo intervalo de terça maior entre a quinta e a sétima maior do acorde de Dó. Em seguida, o intervalo é trabalhado na forma de um motivo, onde apojaturas são colocadas entre as notas do intervalo para só depois, no final do motivo, o salto subseqüente ser executado sobre o acorde de Ré menor.

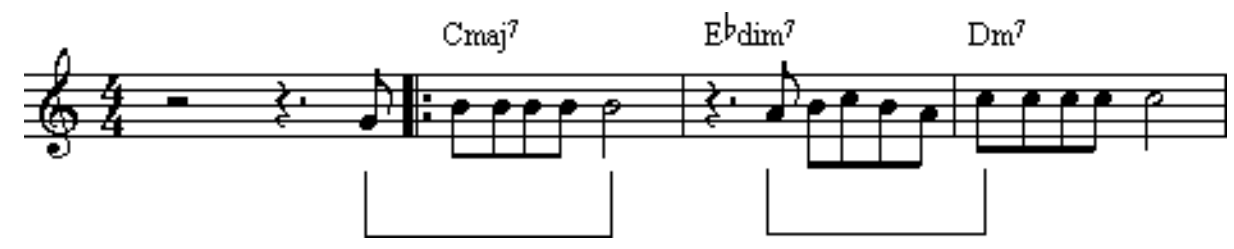

Ilustração 1

Esse motivo é repetido mais duas vezes, em forma de gradatio ascendente, durante a primeira seção da canção. Um novo argumento surge na parte seguinte, segundo o sistema retórico, o confutatio. Este novo elemento é em forma de saltos de longa duração, que juntos também formam um gradatio, mas desta vez descendente. Para Piedade, nesta seção, apesar da fórmula de compasso ser quatro por quatro, revela-se uma intenção de evocar o espírito da valsa brasileira, remetendo a uma tópica chamada época-de-ouro

5 As letras das canções se encontram em anexo.

6 As Partituras das canções se encontram em anexo, com anotações analíticas.

7 Pode-se imaginar que a pessoa chamada "Dotô" seja um advogado, porém é interessante pensar que talvez possa ser um médico. 
(PIEDADE, 2006, pp. 65-66).

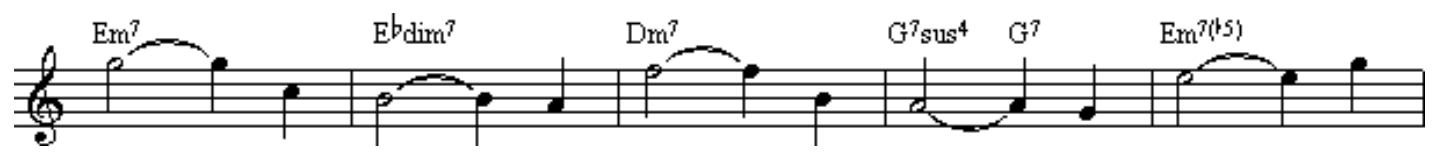

\section{Ilustração 2}

Esta primeira parte é repetida do início ao fim do tema principal, ou propositio, para então ir à parte $\mathrm{C}$ da música, que constitui um confirmatio, onde o motivo da terça é retomado e trabalhado de forma descendente para se chegar à conclusão da canção, o peroratio.

O intervalo de terça também é o argumento principal da canção Incompatibilidade de gênios, iniciada igualmente com o salto do quinto grau para o sétimo do acorde de tônica, Lá menor.

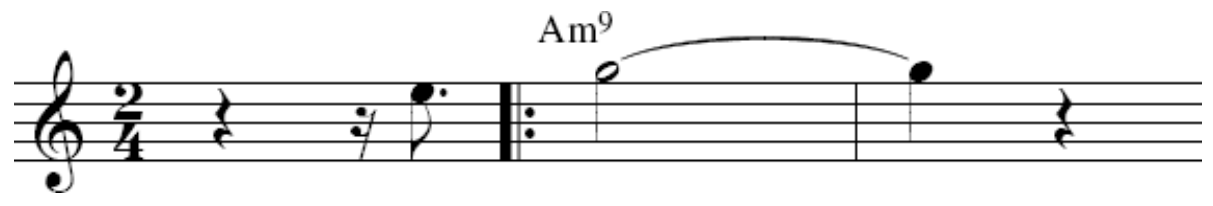

Ilustração 3

Após ser apresentado no exordium, surge no narratio o motivo principal desta música, que será repetido até o final à maneira de um gradatio descendente, sendo que a última nota é sempre uma terça abaixo da nota inicial da próxima repetição do motivo.

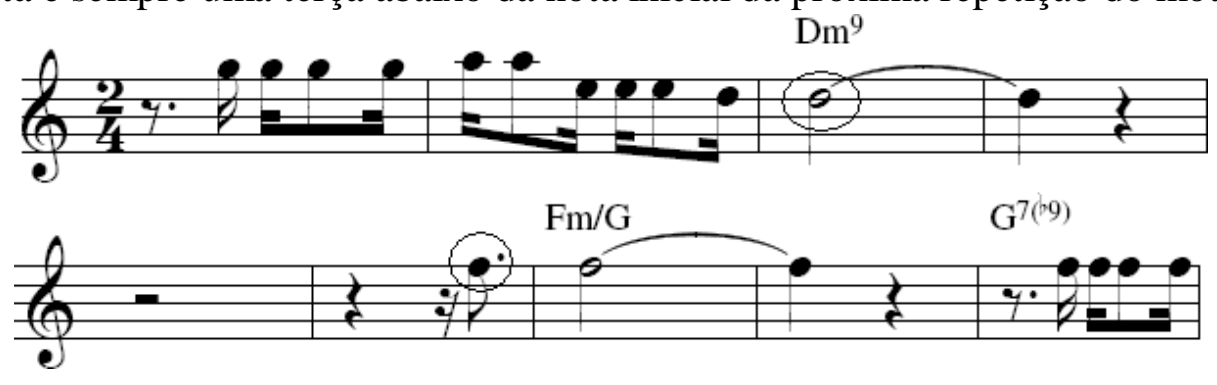

Ilustração 4

No confutatio, aparece um motivo em forma de arpejo, com caráter conclusivo. A música é repetida e, ao chegar no final, é executado o motivo do arpejo para se encerrar a música, caracterizando assim o peroratio. 
I PARTITURAS:

\section{Eu sei que vou te amar}

Tom Jobim \& Vinicius de Moraes

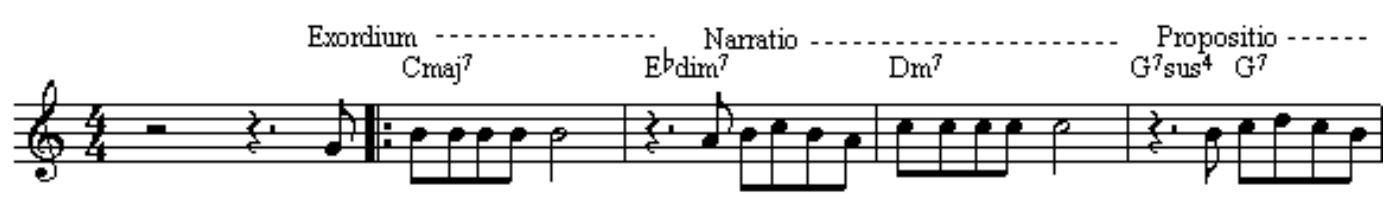

Confutatio - - -
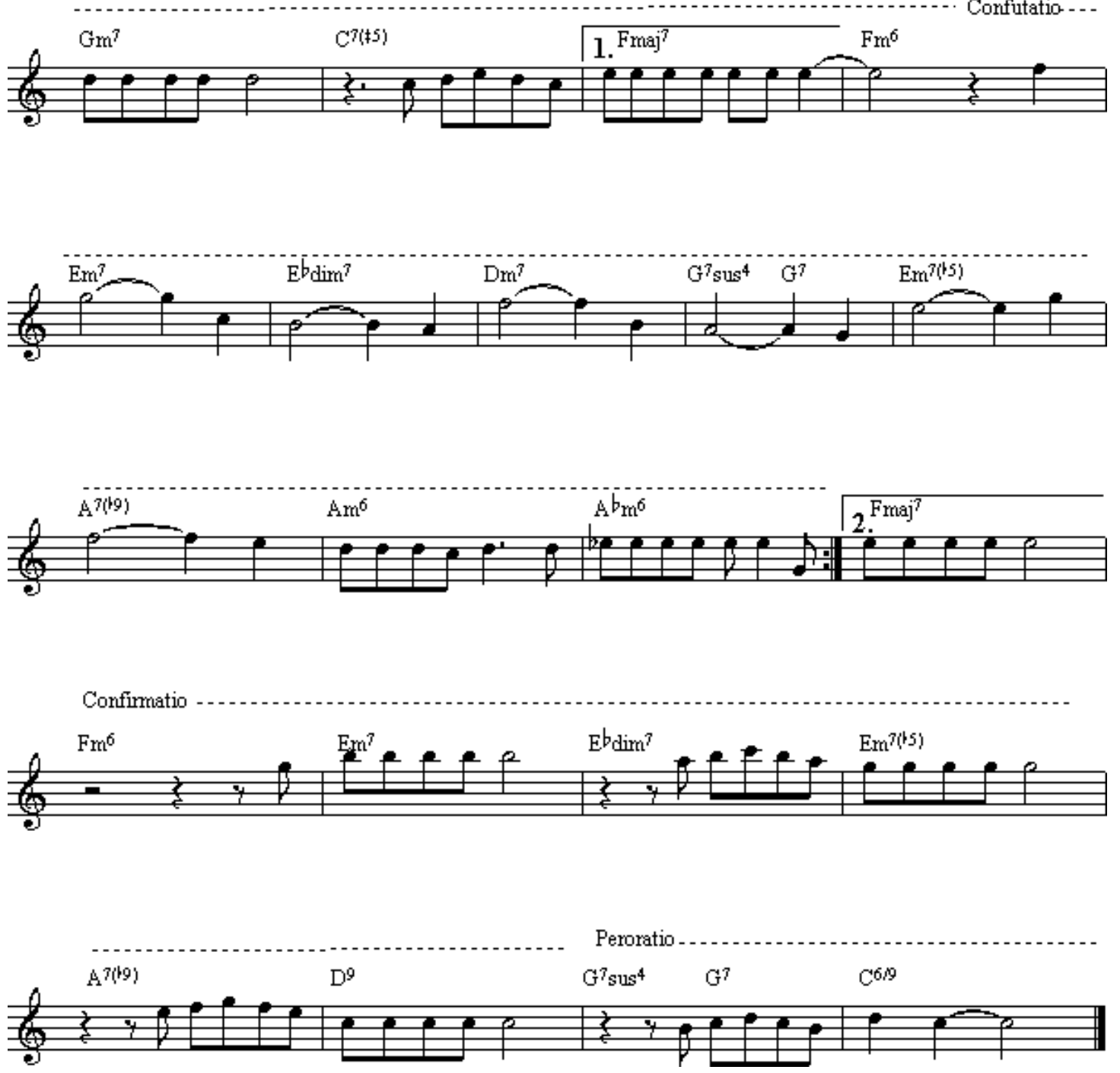

Ilustração 5

DAPesquisa, Florianópolis, v.2, n.4, p. 463-471, 2007. 


\section{Incompatibilidade de Gênios}

João Bosco \& Aldir Blanc
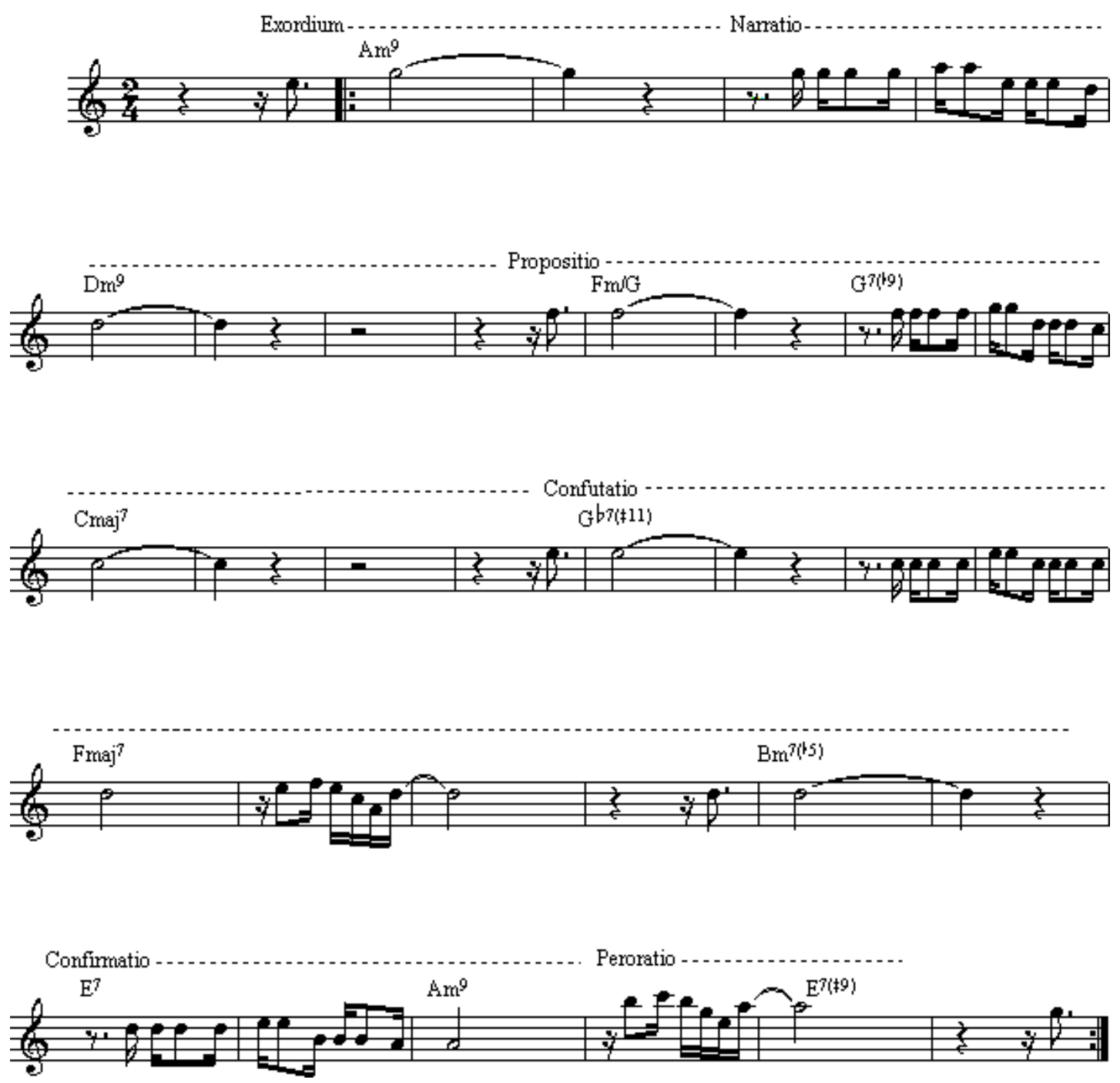

Ilustração 6

\section{LETRAS:}

Música: Eu sei que vou te amar

Autores: Tom Jobim e Vinicius de Moraes

CD: Por Toda a Minha Vida - 1959

Eu sei que vou te amar

Por toda a minha vida, eu vou te amar

Em cada despedida, eu vou te amar

Desesperadamente

$\mathrm{Eu}$ sei que vou te amar

E cada verso meu será

DAPesquisa, Florianópolis, v.2, n.4, p. 463-471, 2007. 
Prá te dizer que eu sei que vou te amar

Por toda a minha vida

Eu sei que vou chorar

A cada ausência tua eu vou chorar

Mas cada volta tua há de apagar

$\mathrm{O}$ que esta ausência tua me causou

Eu sei que vou sofrer

A eterna desventura de viver

À espera de viver ao lado teu

Por toda a minha vida

Música: Incompatibilidade de Gênios

Autores: João Bosco e Aldir Blanc

CD: Galos de Briga - 1976

Dotô, jogava o Flamengo, eu queria escutar.

Chegou, mudou de estação, começou a cantar.

Tem mais, um cisco no olho, ela em vez de assoprar,

sem dó, falou que por ela eu podia cegar.

Se eu dou um pulo, um pulinho, um instantinho no bar,

bastou, durante dez noites me faz jejuar.

Levou as minhas cuecas prum bruxo rezar.

Coou meu café na café na calça pra mês segurar.

Se eu to devendo dinheiro e vêm me cobrar,

Dotô, a peste abre a porta e ainda manda sentar.

Depois, se eu mudo de emprego que é pra melhorar,

vê só, convida a mãe dela pra ir morar lá.

Dotô, se eu peço feijão, ela deixa salgar.

Calor, mas veste casaco pra me atazanar.

E ontem, sonhando comigo, mandou eu jogar

no burro e deu na cabeça a centena e o milhar.

Ai, quero me separar.

\section{CONCLUSÃO}

Nesta comunicação, exploramos a aplicação do sistema retórico para o caso de duas canções da MPB, procurando tecer comentários comparativos. Evidentemente, um sistema semiótico do século XVII, tal como descrevemos na primeira parte deste texto, não pode ser diretamente adequado para compreender canções populares do século XXI, e, por isso, os termos aqui empregados resultam de um exercício preliminar em busca de um sistema retórico próprio, que cremos haver na MPB. Acreditamos que uma retórica se faz presente na música brasileira, articulando figuras musicais que "colocam em jogo identidades e referências culturais que constroem um universo musical entendido como brasileiro" (PIEDADE, 2006, pg. 66). 
Referências:

ANDRADE, Mário de; ALVARENGA, Oneyda; TONI, Flavia Camargo. Dicionário musical brasileiro. Brasilia: Ministério da Cultura; Belo Horizonte: Itatiaia, 1989.

BARTEL, Dietrich. Musica Poetica: musical-rethorical figures in German Baroque. Lincoln: University of Nebraska Press, 1997.

BASTOS, Rafael Menezes. A origem do samba como invenção do Brasil: Sobre "feitio de oração" de Vadico e Noel Rosa (Porquê as canções tem letra). Revista Brasileira de Ciências Sociais n.31 ano XXI, p. 156-177, São Paulo, SP, 1996.

BUELOW, George. "Rhetoric and Music". In Stanley Sadie (ed.) The New Grove Dictionary of Music and Musicians. MacMillan, 1980.

CANO, Rubén López. Musica y Retórica en el Barroco. México: Universidad Nacional Autonoma de México, 2000.

CAVAZOTTI, André (org.) A semântica das paixões: estudos sobre a retórica na música barroca. Programa de Pós-Graduação em Música da UFMG, 2005.

CIVRA, Ferrucio. Musica Poetica. Torino: Utet, 1991.

FRITH, S. Why do songs have words? In: "Music for Pleasure", do autor, New York, Routledge, 1988, pp. 105-128.

JACOBS, Arthur. Dicionário de Música. Lisboa: Dom Quixote, 1978.

PIEDADE, Acácio Tadeu de Camargo. Expressão e sentido na música brasileira: retórica e análise musical. In: SIMPÓSIO DE PESQUISA EM MÚSICA, 3, 2006, Curitiba. Anais do Simpósio de pesquisa em música, 3. Curitiba: DeArtes UFPR, 2006. p. 69-74.

TATIT, Luiz. Semiótica da canção: melodia e letra. São Paulo: Escuta, 1994.

TATIT, Luiz. O Cancionista: Composição de canções no Brasil. São Paulo: EDUSP, 1996. 